\title{
EXPERIMENTAL STUDY OF FLOW BEHAVIOR AROUND SUBMERGED SPUR-DIKE ON RIGID BED
}

\author{
Emad ELAWADY ${ }^{1}$, Masanori MICHIUE ${ }^{2}$ and Osamu HINOKIDANI ${ }^{3}$ \\ ${ }^{1}$ Student Member of JSCE, Ph.D. student, Dept. of Civil Eng., Tottori University (Koyama 680, Japan) \\ ${ }^{2}$ Fellow of JSCE, Dr. Eng., Prof., Dept. of Civil Eng., Tottori University (Koyama 680, Japan) \\ ${ }^{3}$ Member of JSCE, Dr. Eng., Assoc. Prof., Dept. of Civil Eng., Tottori University (Koyama 680, Japan)
}

\begin{abstract}
This paper presents the results of an experimental study of flow behavior around submerged dikes on rigid bed. The studies of flow behavior including water surface profiles and velocity profiles around a single dike with different cases were carried out with steady uniform flow on smooth rigid bed. It is observed that, the disturbance occurred in the water surface profiles and the velocity profiles for a short distance upstream the dike and for a longer distance downstream the dike. The flow patterns around fullysubmerged dike and just-submerged dike had a different phenomenon such as: A rise in the water surface level upstream the dike and a drop in the water surface level downstream the dike. The separation flow zones were different in each case depending on the kind of the dike.
\end{abstract}

Key words: submerged spur-dikes, velocity profiles, water surface, rigid bed.

\section{INTRODUCTION}

Rivers in alluvial areas carry sediment in varying portions depending on the material constituting the bed and the banks. The discharge of the river varies from season to season considerably. The sediment concentration is very high during the floods and very low during the low stages of rivers. The movement of sediment always causes scour of the river bed and the banks. Training structures are required to resist the current and to protect the channel against the changes. There are many training structures for this purpose such as: spurdikes, longitudinal dikes, bank protection by means of revetment...etc.

Spur-dikes are a kind of river training works constructed at an angle to the flow direction beginning at the regulation line with a head ${ }^{1)}$. Spurdikes are frequently used for one or more of the following purposes:

- Training of the stream flow.

- Protection of the stream bank from erosion.

- Improvement of depth for navigation.

Most of the experimental studies concerning local scour and flow behavior around spur-dikes have been performed to observe downstream flows, in which the flow depths were less than the height of the spur-dike model ${ }^{2), 3)}$. Also in most of the previous studies, only one type of dikes has been used which is always $90^{\circ}$ spur-dikes and expressed the results in dimensionless forms. Because of that, observing the flow behavior around submerged dikes are required to spot on the three-dimensional flow patterns around the dikes which are very complicated $^{4)}$.

In the current study, the spur-dikes that have been used can be classified as impermeable, straight, and (fully-submerged \& just-submerged) spur-dikes. In addition, the inclination angles of the spur-dike were deflecting, repelling and attracting. The spur-dike was kept at left side wall of the flume through the flow direction in this experimental study.

\section{EXPERIMENTS}

\section{(1) Summary of Experiments}

The experiments were conducted at the Hydraulics Laboratory, Department of Civil Engineering, Tottori University, Japan. A tilting flume is $0.4 \mathrm{~m}$ wide, $0.4 \mathrm{~m}$ deep and $18 \mathrm{~m}$ in length. The central $8 \mathrm{~m}$ of the flume is equipped with transparent walls. The bed surface of the flume is steel painted with white spray paint material to keep the bed smooth as well as rigid. The water is supplied to the system from a constant head, overhead tank through a $0.2 \mathrm{~m}$ diameter delivery pipe. The discharge is controlled by a valve fitted in the delivery pipe. 


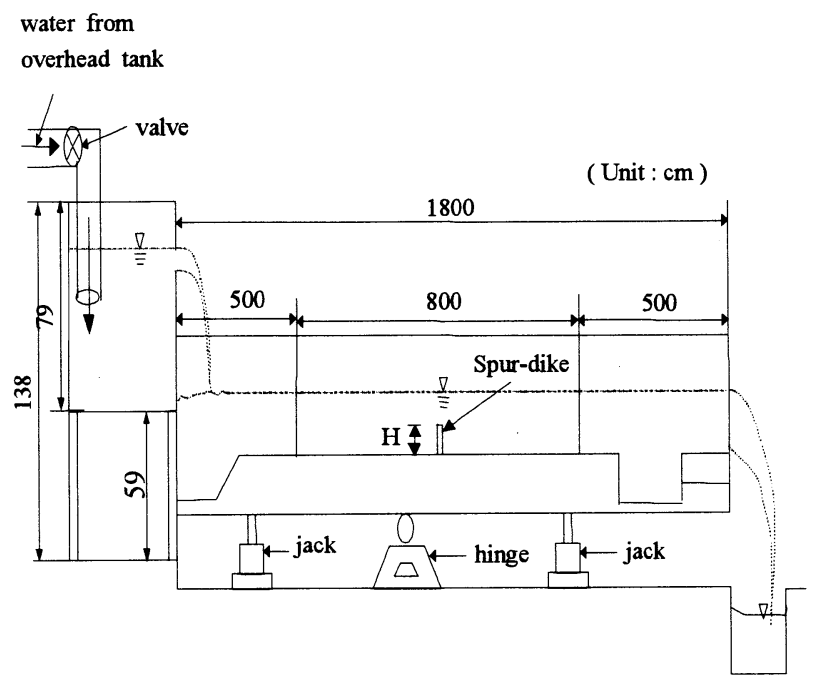

Fig. 1 Details of the experimental set-up

The discharge was measured by a triangular weir that was calibrated prior to the experiment. Water surface level was measured with point gauge. Flow velocities were measured with Acoustic Doppler Velocity (ADV) anemometer, which can measure 3D components of flow velocity. The details of the experimental set-up are shown in Fig. 1, and the experimental cases are summarized in Table 1.

Table 1 The experimental cases

\begin{tabular}{|c|c|c|c|}
\hline $\begin{array}{c}\text { Case } \\
\text { No. }\end{array}$ & $\begin{array}{c}\text { Type of } \\
\text { the dike }\end{array}$ & $\theta$ & $\begin{array}{c}\mathrm{H} \\
(\mathrm{cm})\end{array}$ \\
\hline 1 & Deflecting & $90^{\circ}$ & 5 \\
\hline 2 & Repelling & $60^{\circ}$ & 5 \\
\hline 3 & Attracting & $120^{\circ}$ & 5 \\
\hline 4 & Deflecting & $90^{\circ}$ & 10 \\
\hline 5 & Repelling & $60^{\circ}$ & 10 \\
\hline 6 & Attracting & $120^{\circ}$ & 10 \\
\hline
\end{tabular}

\section{(2) Experimental procedure}

In the current study, the longitudinal surface slope of the flume was $1 / 2500$ for all cases. Before the beginning of the experiment, the flume was operated with different slopes and different discharges until it was adjusted to the suitable slope with suitable discharge, which gave the steady uniform flow conditions.

The spur-dike model used was a transparent impermeable straight acrylic sheet placed at the left side wall of the flume to the flow direction. The height of the dike was $5 \mathrm{~cm} \mathrm{\&} 10 \mathrm{~cm}$, the length of the dike in plan was $10 \mathrm{~cm}$ and the thickness was $1.5 \mathrm{~cm}$. The discharge valve was slowly opened and water was then allowed to flow through the flume. The discharge valve was slowly adjusted to give a supply of the flow at a constant rate of 0.015 $\mathrm{m}^{3} / \mathrm{sec}$.

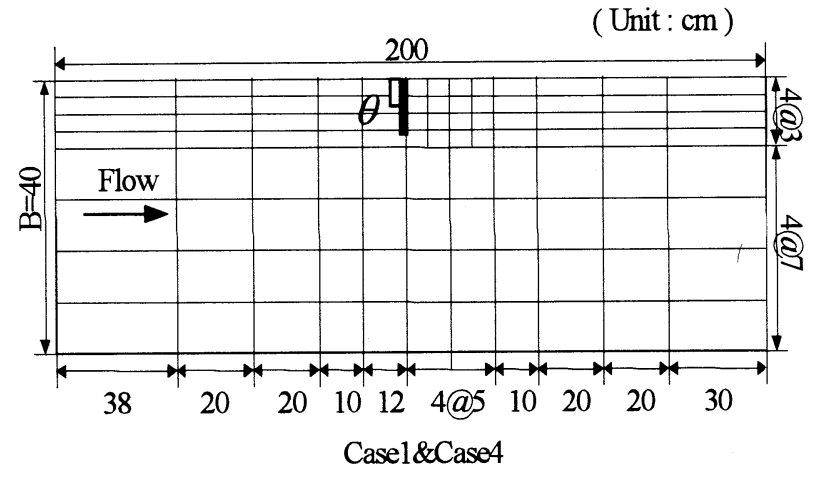

Deflecting spur-dike

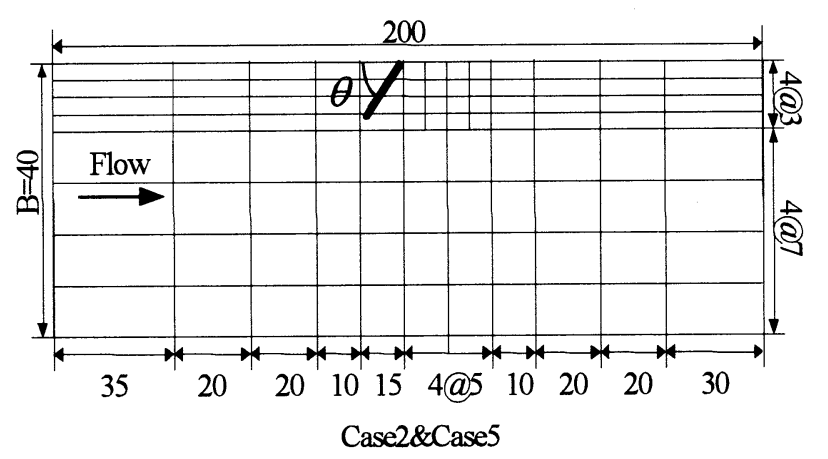

Repelling spur-dike

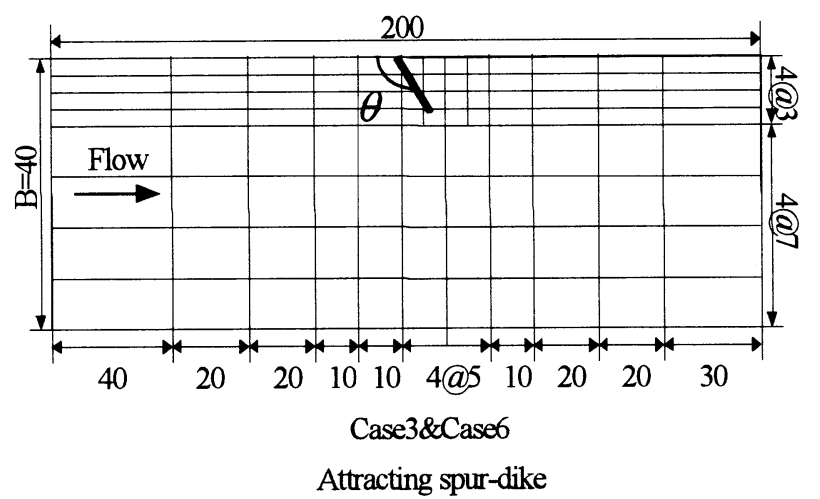

Fig.2 Measurements locations

The tailgate was completely opened, so that there was no influence of tailgate on the flow and the water surface slope, which was parallel to the flume bed. In each case, we had a different mesh to decide the measurement points, which were dependent on the direction of the spur-dike in the plan. The number of measurement points in the vertical was ten points every $1 \mathrm{~cm}$ above the bed of the flume. Across the channel, the number of measurement points was seven points at $3,6,9,12,19,26$ and 33 $\mathrm{cm}$ from the left side wall. Along the flow direction, the number of the measurement points was fourteen points with different spaces in each case. The measured region in the longitudinal direction was $100 \mathrm{~cm}$ long upstream the spur-dike and $100 \mathrm{~cm}$ long downstream the spur-dike as shown in Fig. 2. The data recording time for each point was 30 seconds with a frequency of $25 \mathrm{~Hz}$. It means that we 


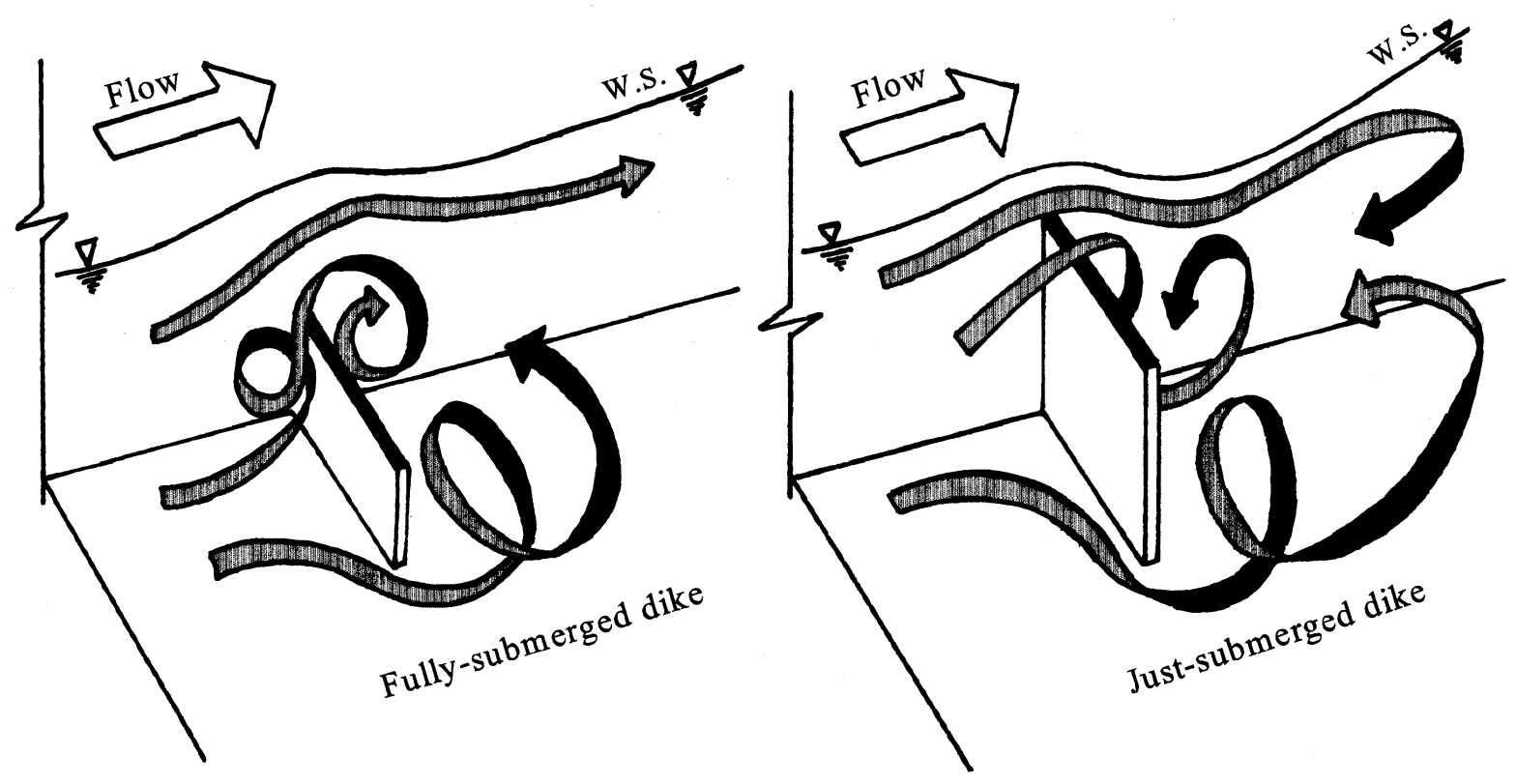

Fig.3 Flow behavior around deflecting spur-dike

had 750 recording data for each point, and we got the averaged value from this data.

Because of the dimensions of the velocitymeasuring instrument, we could not observe locations within the reach of $9 \mathrm{~cm}$ upstream of the dike.

\section{(3) Flow characteristics}

The flow characteristics in all cases of the experiment were constant as it is shown in Table 2.

Table 2 The flow characteristics

\begin{tabular}{|l|l|}
\hline Uniform flow depth $(\mathrm{d})$ & $10.3 \mathrm{~cm}$ \\
\hline Width of flume $(\mathrm{B})$ & $40.0 \mathrm{~cm}$ \\
\hline Discharge $(\mathrm{Q})$ & $0.015 \mathrm{~m}^{3} / \mathrm{sec}$ \\
\hline Mean velocity $(\mathrm{v})$ & $0.37 \mathrm{~m} / \mathrm{sec}$ \\
\hline Shear stress $\left(\mathrm{u}^{*}\right)$ & $0.020 \mathrm{~m} / \mathrm{sec}$ \\
\hline Channel bed slope $\left(\mathrm{S}_{0}\right)$ & $1 / 2500$ \\
\hline Froude number $\left(F_{r}\right)$ & 0.365 \\
\hline Manning roughness $(\mathrm{n})$ & 0.012 \\
\hline
\end{tabular}

\section{EXPERIMENTAL RESULTS}

\section{(1) Behavior of flow}

The behavior of flow around the deflecting spurdike is shown in Fig. 3, as observed from the experiments but could not measure it, because of the dimensions of the anemometer. In case of fully-

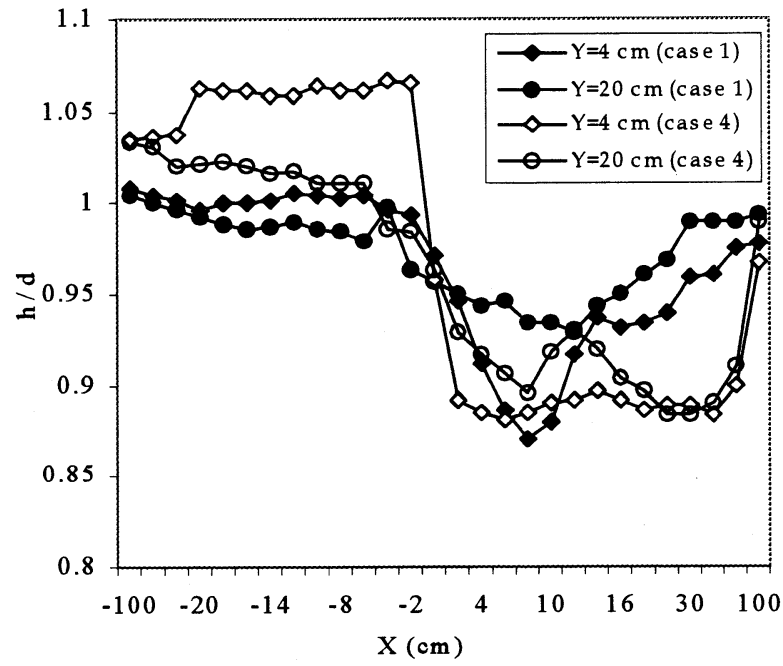

Fig.4 Longitudinal water surface profile

submerged dike, the bed layers of the flow upstream has a small eddy, it moves above the dike with another eddy downstream. Other flow layers move longitudinally with various velocities. While in case of just-submerged dike, the bed layers move laterally beside the dike with large velocity without any eddies in the upstream. Other flow layers move with small velocity for long distance downstream the dike.

\section{(2) Water surface profiles}

The longitudinal water surface profiles are shown in Fig. 4. In this figure, the water surface profiles were plotted for two measuring lines for each of 


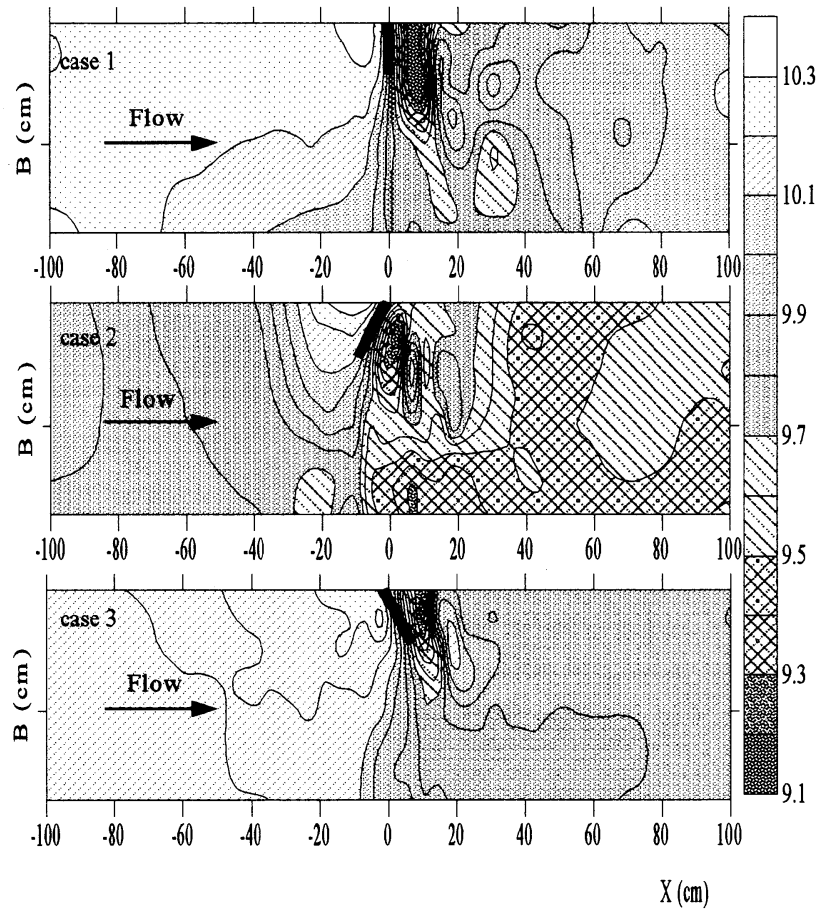

Fig.5-a Fully-submerged dike

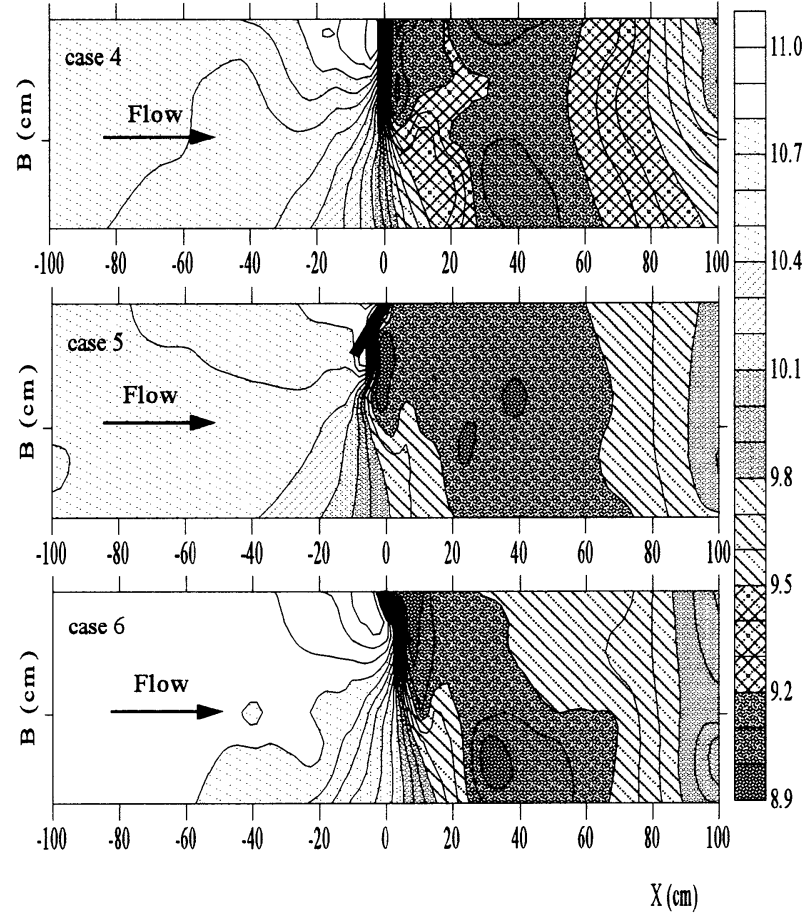

Fig.5-b Just-submerged dike

Fig.5 Water surface contours

case 1 and case 4 . In the figure, axis $X$ is the longitudinal distance from the spur-dike directing to the downstream, and the dike locates at $X=0 \mathrm{~cm}$.

Upstream the dike, the water surface level has big difference between the two cases of study due to a direct effect from the different kinds of dikes in each case. The water surface level in case 1 is not influenced greatly by the dike, especially near to the side wall $(\mathrm{Y}=4 \mathrm{~cm})$. At $\mathrm{Y}=20 \mathrm{~cm}$ the water surface has a small drop within a small distance upstream the dike.

In case 4 the water surface level near to the side wall $(\mathrm{Y}=4 \mathrm{~cm})$ rises up around $0.6 \mathrm{~cm}$ from the uniform water surface level upstream. While at the middle of the flume width $(\mathrm{Y}=20 \mathrm{~cm})$ the water surface level moves down directly, which means that the lateral water surface upstream is influenced by the height of the dike.

Downstream the dike, it seems that the water surface level is completely different in the two cases. In case 1 , there is a big drop in water surface level occurred very close to the dike $(X=16 \mathrm{~cm})$ in the dike side only. While in case 4 , there is a big drop in water surface level occurred within long distance downstream $(X=65 \mathrm{~cm})$ in all flume width not only in the dike side. That drop is usually observed in sub-critical flow passing over a hunch due to the higher energy required upstream to pass the flow through the contraction at the dike.

The water surface contours are shown in Fig. 5-a and Fig. 5-b. In these figures, the difference in
Longitudinal and lateral water surface level is very clear in each case. The drops happened in the water Surface levels were almost parallel to the spur-dike. In addition, it is found that for the same discharge the uniform water surface level upstream had big changes due to the height of the spur-dike. Finally, the water surface level is higher than the initial water surface only upstream of the dike by the length of the dike $(\mathrm{Y}=10 \mathrm{~cm})$. Moreover, it depends on the height and the inclination angle of the spurdike in plan.

\section{(3) Velocity distributions}

The velocity vectors around the dike in (X-Z) direction for fully-submerged dike are plotted in Fig. 6 for two measuring lines $(Y=6,12 \mathrm{~cm})$.

Upstream area: The velocity was small near to the bed within the dike length, while it was bigger above the dike height.

Downstream area (from $X=0$ to $X=30 \mathrm{~cm}$ ): There was eddy in (X-Z) direction for a small distance downstream the dike within the length of the dike only $(\mathrm{Y}=10 \mathrm{~cm})$. The center of this eddy locates at about $X=10 \mathrm{~cm}$. In case 1 and case 3, a separation flow zone locates from the spur-dike position to $X=25 \mathrm{~cm}$ within the height of the dike $(Z=5 \mathrm{~cm})$. While in case 2 , a separation flow zone was very limited within $X=10 \mathrm{~cm}$ downstream the dike.

At $\mathrm{Y}=12 \mathrm{~cm}$, in all three cases the velocity was very large above the dike height and smaller towards the bed layers. 

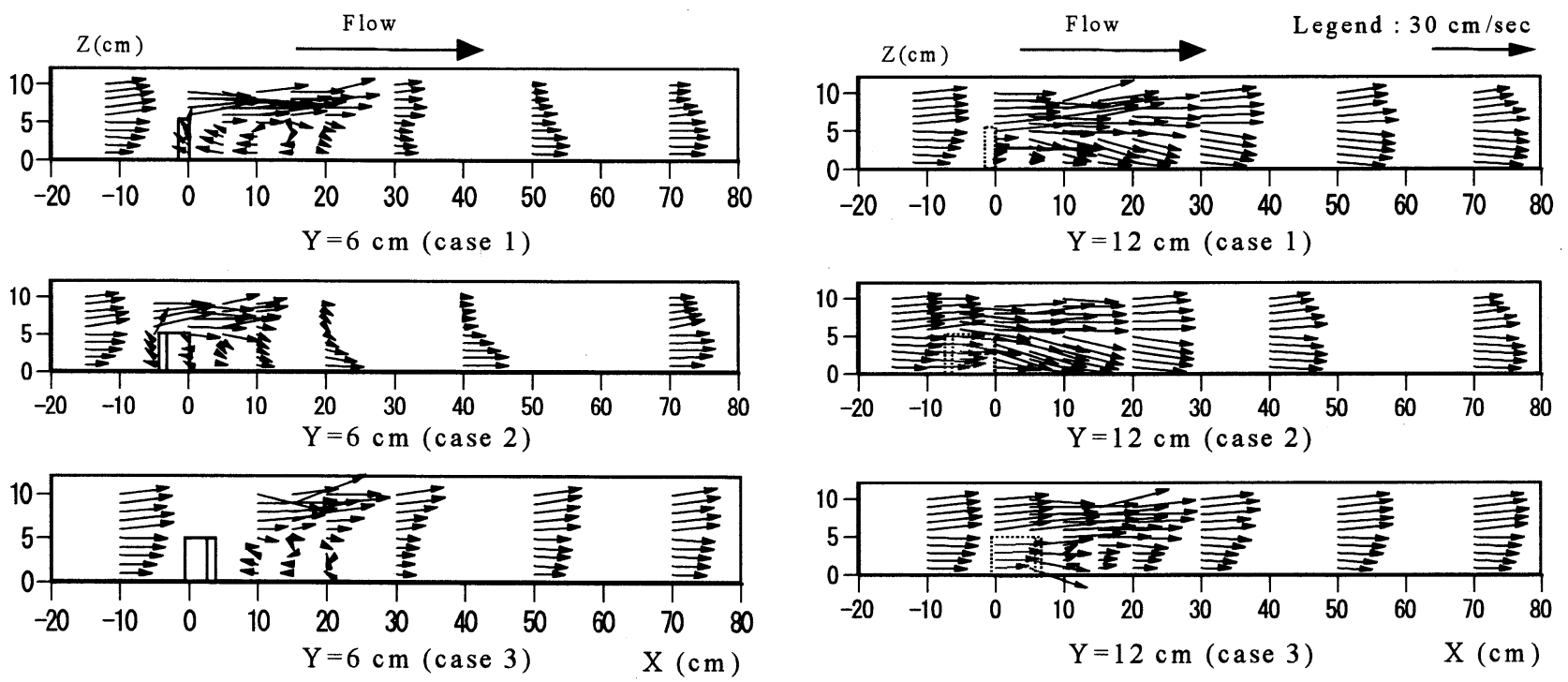

Fig.6 Velocity vectors for fully-submerged dike

Downstream area far from the dike region (from $\mathrm{X}=30$ to $\mathrm{X}=80 \mathrm{~cm}$ ): Both of case 1 and case 2 follows the same behavior. At $Y=6 \mathrm{~cm}$, the velocity vectors near to the bed larger than those at the surface layers. At $\mathrm{Y}=12 \mathrm{~cm}$, all velocity vectors are large from the bed to the surface. However, in case 3 , there was a little difference near to the bed. Which means that even with same height of the dike, the inclination angle also has a strong effect on the behavior of flow especially downstream the spur-dike.

The velocity vectors around the dike in $(\mathrm{X}-\mathrm{Z})$ direction for just-submerged dike are plotted in Fig. 7. Due to a direct effect of the height of the dike, the velocity vectors have different phenomenon from the previous cases especially downstream the spur-dike.
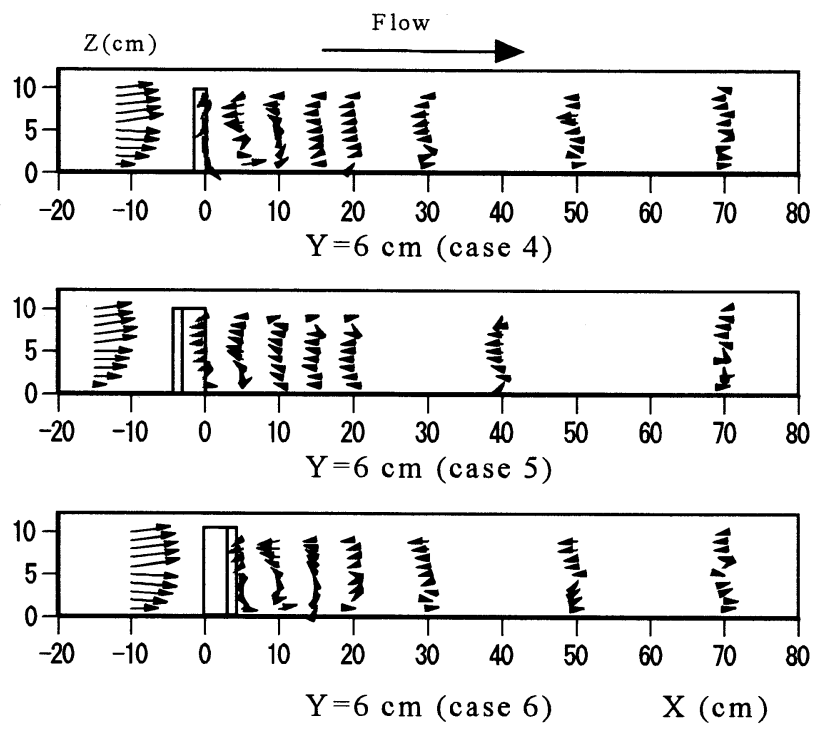

Downstream area: In all three cases at $\mathrm{Y}=6 \mathrm{~cm}$, there was a dead water zone with velocity near to zero from the bed to the surface layer. A separation flow zone is found to locate behind the spur-dike for a long distance within $X=70 \mathrm{~cm}$ by the dike length $(\mathrm{Y}=10 \mathrm{~cm})$. In case 4 and case 6 , eddy is observed to locate just downstream the dike in $(X-Z)$ direction, the center of this eddy locates at about $\mathrm{X}=5 \mathrm{~cm}$.

At $\mathrm{Y}=12 \mathrm{~cm}$, the velocity vectors have small positive values until $X=40 \mathrm{~cm}$, then it starts to turn to large velocity at bed layers.

Generally speaking, the height of the spur-dike and the inclination angle of the spur-dike with the direction of flow have direct effects on the behavior of flow as well as the velocity distributions as discussed before.
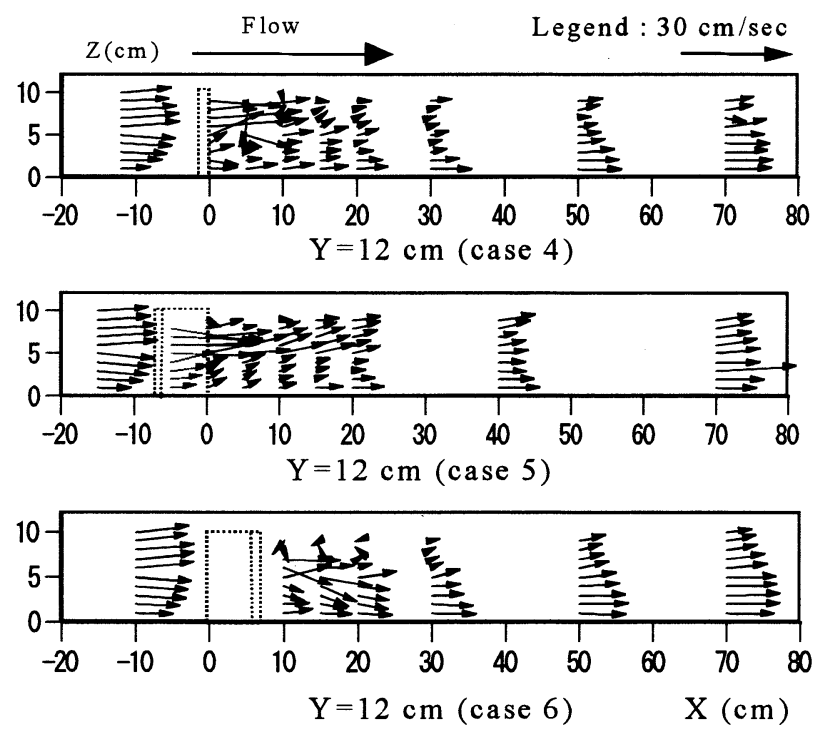

Fig.7 Velocity vectors for just-submerged dike 


\section{CONCLUSIONS}

This study has shown that when spur-dike with different heights are placed in a channel, it causes a significant disturbance to the flow behavior. It is observed that, the disturbance occurs in the water surface profiles and the velocity profiles for a short distance upstream the dike and for a longer distance downstream the dike. The flow patterns around fully-submerged dike and just-submerged dike have a different phenomenon such as: The rise in the water surface level upstream the dike and the drop in water surface level downstream the dike, which is very clear as shown in Fig. 8. The separation flow zones are different in each case depending on the kind of the dike. Therefore, the height of the river structures (like spur-dike) must be considered during the design because of its influence on the flow behavior such as water depth and flow velocity as discussed in this paper.

\section{NOTATION}

The following symbols are used in this paper:

$\theta=$ angle of inclination of spur-dike with the direction of flow

$\mathrm{H}=$ height of the spur-dike

$\mathrm{d}=$ uniform flow depth

$\mathbf{h}=$ water depth

$\mathrm{B}=$ width of flume

$\mathrm{v}=$ mean velocity of the flow

$\mathrm{X}=$ longitudinal distance from spur-dike directing to downstream

$\mathrm{Y}=$ lateral distance from flume wall

$Z=$ vertical height from flume bed
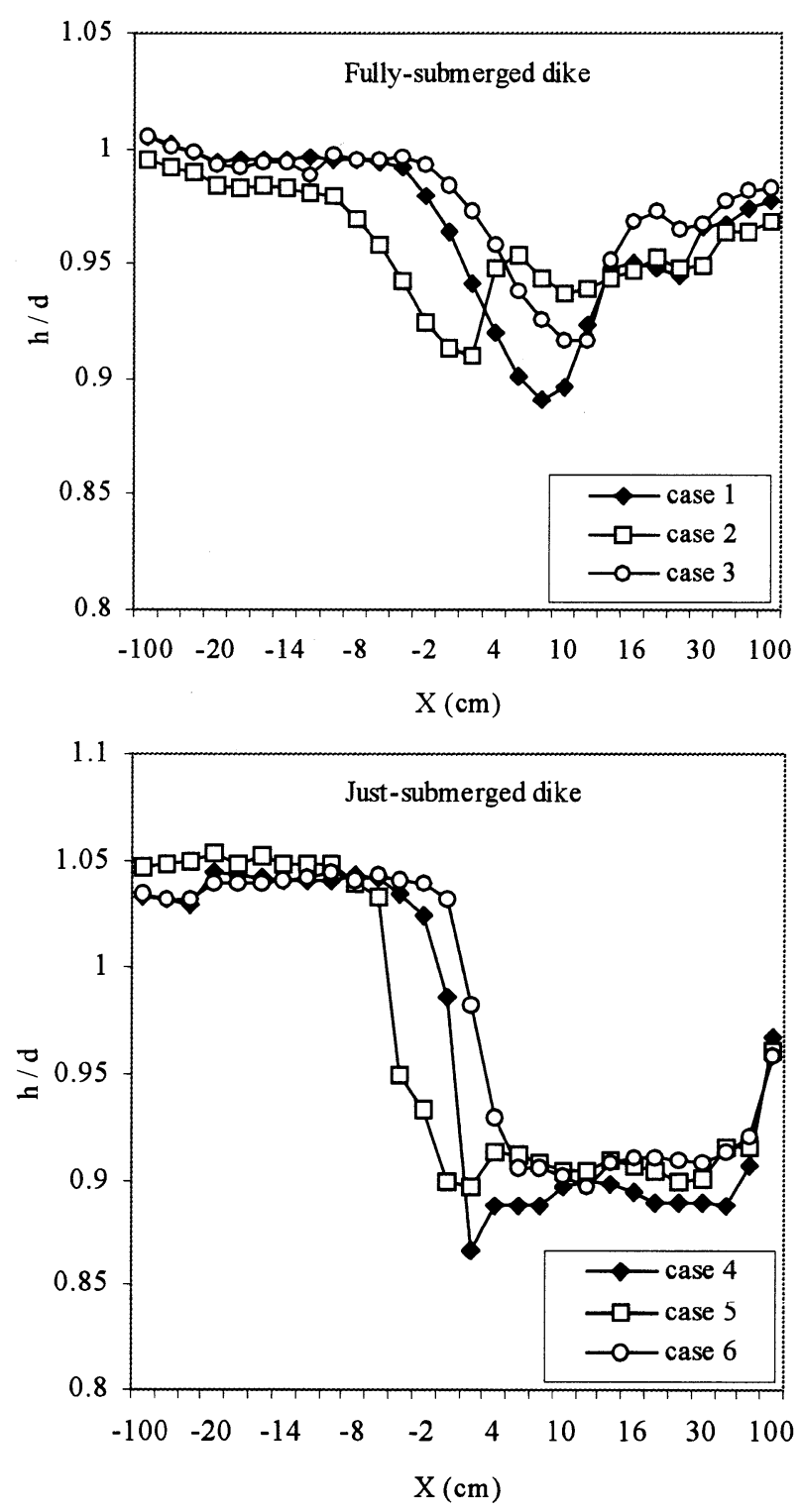

Fig.8 Averaged longitudinal water surface profiles

5) Joe, C. Willis: Near-bed velocity distribution, Journal of Hydraulic Engineering, ASCE, Vol. 111, and No.5, pp.741753, 1985.

6) Ferro, V. and Baiamonte, G.: Flow velocity profiles in gravel-bed rivers, Joumal of Hydraulic Engineering, ASCE, Vol. 120, and No.1, pp.60-80, 1994.

7) French, R. H.: Open channel hydraulic, Mc Graw-Hill, 1986.

8) Chen, F. Y. and Ikeda, S.: Horizontal separation flows in shallow open channels with spur-dikes, Journal of Hydroscience and hydraulic Engineering, Vol. 15, No. 2, pp.15-30, 1997. 